\title{
Natural Nanoskin ACT Management of the Rare Disease as Burnt Patient with Epidermolysis Bullosa and Stevens-Johnson
}

\author{
${\text { Pierre Basmaji }{ }^{1} \text {, Vânia Martins }{ }^{1} \text {, Mohamed Kanjo }}^{2}$ \\ ${ }^{1}$ Innovatecs Biotechnology Research Center, São Carlos, Brazil \\ ${ }^{2}$ G.E.M International-G E M Medical Supplies Trading L.L.C., Sharjah, UAE \\ Email: Mohamed.kanjo@gemint-co.com, vaniamel124@gmail.com, nanoskin.healing@gmail.com
}

How to cite this paper: Basmaji, P., Martins, V. and Kanjo, M. (2020) Natural Nanoskin ACT Management of the Rare Disease as Burnt Patient with Epidermolysis Bullosa and Stevens-Johnson. Journal of Biomaterials and Nanobiotechnology, 11, 188-194. https://doi.org/10.4236/jbnb.2020.113012

Received: May 2, 2020

Accepted: June 6, 2020

Published: June 9, 2020

Copyright $\odot 2020$ by author(s) and Scientific Research Publishing Inc. This work is licensed under the Creative Commons Attribution-NonCommercial International License (CC BY-NC 4.0).

http://creativecommons.org/licenses/by-nc/4.0/

\begin{abstract}
Epidermolysis Bullosa (EB) is a group of rare genetic skin conditions, which is characterised by extremely fragile skin and recurrent blister formation, resulting from minor mechanical friction or trauma. Sufferers of EB have compared the sores to third-degree burns. Stevens-Johnson syndrome is a rare but very serious skin problem, which causes the appearance of reddish lesions throughout the body and other changes, such as difficulty in breathing and fever, which can endanger the life of the affected person. The aim of this study was to show efficacy of a NANOSKIN ACT, AND NANOSKIN ACT SOFT wound dressing on the wound care management in patients with $\mathrm{EB}$ AND Stevens-Johnson syndrome (SJS).
\end{abstract}

\section{Keywords}

Nanoskin ACT Bacterial Cellulose, Epidermolysis Bullosa (EB), Rare Disease, Wound Healing, Tissue Regeneration

\section{Introduction}

Inherited epidermolysis bullosa (EB) is a group of genetically transmitted skin disorders characterized by spontaneous blistering or blistering caused by minor trauma [1] [2]. The cause of EB is a mutation of various structural proteins in the skin resulting in various levels of tissue separation within the dermal-epidermal basement membrane zone [3].

The presence of chronic multiple wounds makes the management of EB difficult and complex. 4 patients with $\mathrm{EB}$ require a non-adherent dressing to avoid trauma and bleeding to the skin on removal. 
Traditionally, gauze soaked with normal saline and classical wound dressing has been used to treat wounds. Nanotechnologies wound dressings create a moist environment to provide the optimal conditions for wound healing [4] [5] [6].

Nanoskin ADVANCE CELL THERAPY (ACT) is established as a newest biomaterial and it can be used for medical applications. In addition, it has called attention for uses such as membrane for wound care and tissue engineering. The ideal dressing Nanoskin ACT SOFT made from vegetal stem cell of green tea should be able to maintain humidity at the wound dressing interface, remove excess exudates, permit the exchange of gases between the wounded tissue and the environment, provide thermal insulation, be impermeable to microorganisms, be biocompatible, natural, be removable without causing trauma to the wound.

\section{Stevens-Johnson syndrome (SJS)}

Stevens-Johnson syndrome (SJS) and toxic epidermal necrolysis (TEN) are uncommon, acute and potentially life-threatening adverse cutaneous drug reactions, often related to drug use. They are the result of extensive death of keratinocytes, which leads to the separation of areas of skin in the dermal-epidermal junction, producing the appearance of scalded skin. The disease runs an unpredictable course: An initially benign-appearing dermatosis can progress rapidly [7] [8] [9] [10].

In this work, we show the efficacy of a NANOSKIN ACT wound dressing with NANOSKIN ACT SOFT wound dressing on the wound care management in patients with EB AND-Johnson syndrome (SJS).

\section{Materials and Methods}

\subsection{Materials Nanoskin ACT}

The optimal skin substitute will provide for immediate replacement of both the lost dermis and epidermis, with permanent wound coverage.

Oxygen is a necessary component of normal wound healing and is required for multiple cell functions, including the killing of bacteria by leukocytes. However, the $\mathrm{pH}$ of the wound can affect many factors including oxygen release, angiogenesis, protease activity, and bacterial toxicity. Chronic non-healing wounds have an elevated alkaline environment. Healing occurs more readily in an acid environment. In addition to the effects on protease activity and oxygen release, other effects of lowering the $\mathrm{pH}$ to a more acidic environment are to reduce the toxicity of bacterial end products such as ammonia, enhancing the destruction of abnormal collagen in the ulcer bed, promotion of angiogenesis, increased macrophage and fibroblast activity and control of enzyme activity [11].

The NANOSKIN ACT natural extra cellular matrix release oxygen to the tissue shows decreasing the number of tissue bacteria in infected wounds.

NANOSKIN ACT natural extra cellular matrix release oxygen to the tissue is fiber polysaccharides can significantly promote DNA synthesis and increase cell 
division, thus delaying the aging body. These fibers are of high concentration of flavonoid compounds, diterpene, triterpene, lignans, phenylpropanoids and prenylated acetophenones to strengthen our immunity cells and improve our immune system. Moreover, contain substances such as $\beta$-glucan polysaccharide and significant amount of glucuronic acid, which acts physiologically in the body as an effective detoxifying agent.

\subsection{Nanoskin ACT SOFT}

It's a natural fiber based on polysaccharides composed of hemicelluloses protein. Made from bionanotechnology, it's made up of a random assembly of ribbon shaped fibers less than $2 \mathrm{~nm}$ wide. These fibers themselves are composed of a bundle of much finer micro fibrils of nanometric size.

Nanoskin ACT SOFT indicated to fill irregularities or recesses of the wound bed, and thus facilitate the execution of another membrane plate.

Nanoskin ACT SOFT is suitable for wounds where a conventional dressing does not make an effective coverage of the wound bed and wound with difficult access areas.

Its purpose is to absorb excess exudates from lesions by increasing the residence time of the used dressing and reducing the frequency of change.

\section{Results and Discussion}

\subsection{Case $1 \mathrm{~EB}$}

Patient has 8 years old, many years EB treatment with classical wound dressing without any progress, Figure 1 shows the lesion in all body; (a) before apply Nanoskin ACT, (b) after one month Nanoskin ACT treatment which it can be observed the new skin granulation intense red color and reducing wound size.

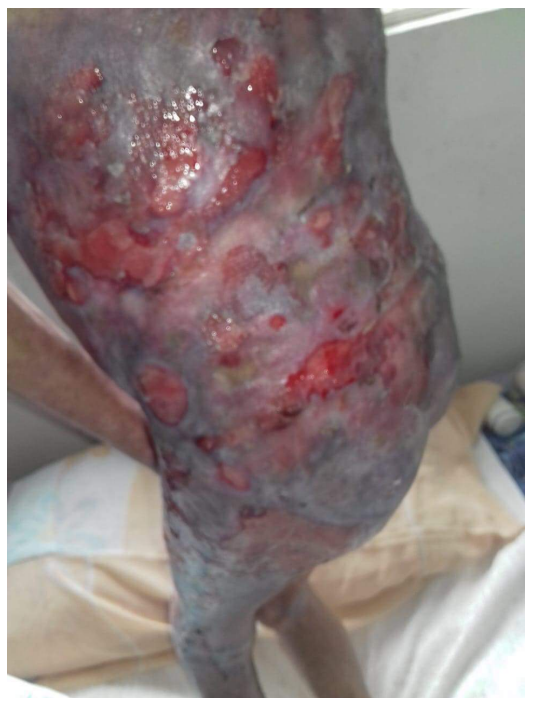

(a)

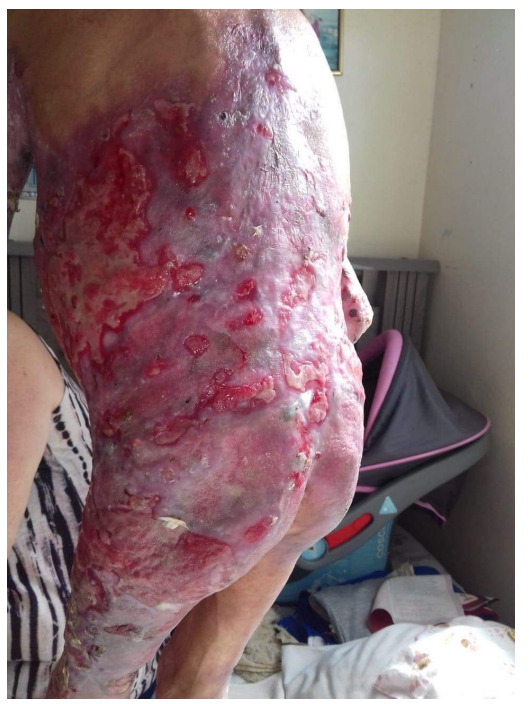

(b)

Figure 1. Epidermolysis Bullosa (EB) affected all the body before and after Nanoskin ACT treatment. 
In Figure 2, We apply Nanoskin ACT together with Nanoskin ACT SOFT, the results was very exciting, we obtain good granulation and epitilization, time treatment was 4 months, (a) before treatment, (b) after 2 months treatment intense red color, (c) after 4 months with new skin regeneration.

As results of EB treatment with Nanoskin ACT and NANOSKIN ACT SOFT, the child said he did not have more pain, slip well, and finally he can take shower, and the medical equip at children institute at Sao Paulo-Brazil decide to sift the consultation for each $4 / 4$ months than $2 / 2$.

\subsection{Case 2-EB}

Child 3 years old with EB present at the body, we start treatment with Nanoskin ACT and Nanoskin ACT SOFT on July 08, 2019. Figure 3(a) and Figure 3(b) Shows the evolution of Eb treatment with nanoskin ACT and nanoskin ACT SOFT.

\subsection{Case 3 (SJS)}

Child one year old with Stevens-Johnson syndrome, Figure 4 shows the baby before treatment (a). (b) after applying Nanoskin ACT and Nanoskin ACT SOFT, treatment has been started with interval time changing every $48 \mathrm{~h}$ and Nanoskin ACT SOFT, (c) complete healing.

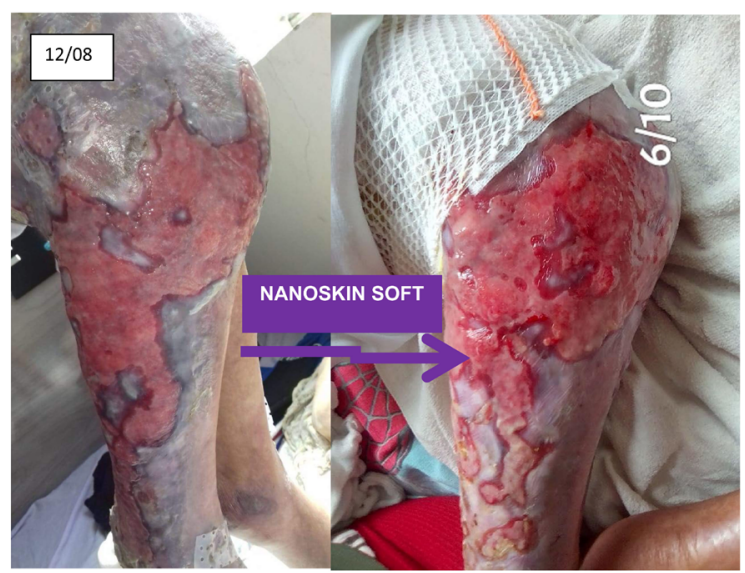

(a)

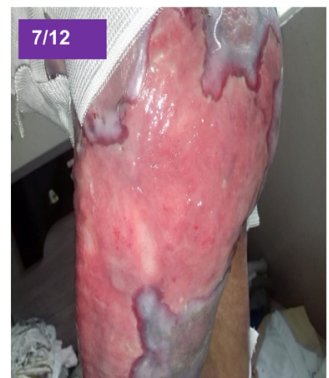

(c) (b)

Figure 2. The evolution of Eb treatment by Nanoskin ACT, and Nanoskin ACT soft. (a) before treatment, (b) after 2 months treatment intense red color, (c) after 4 months with new skin regeneration. 


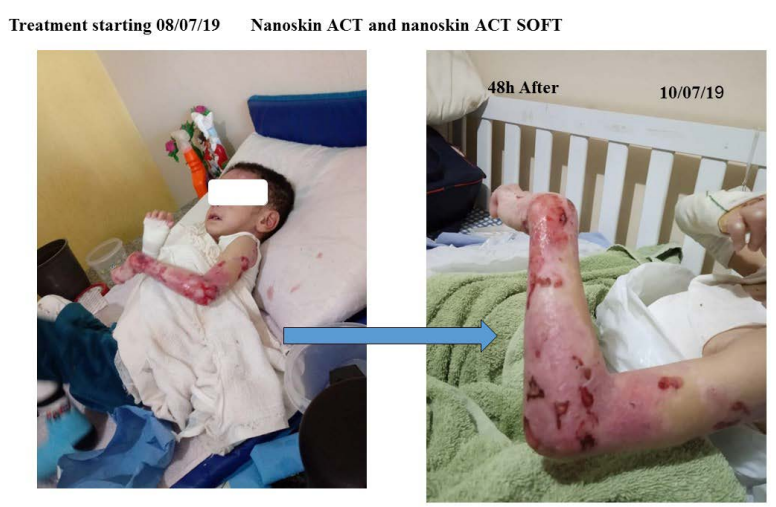

(a)
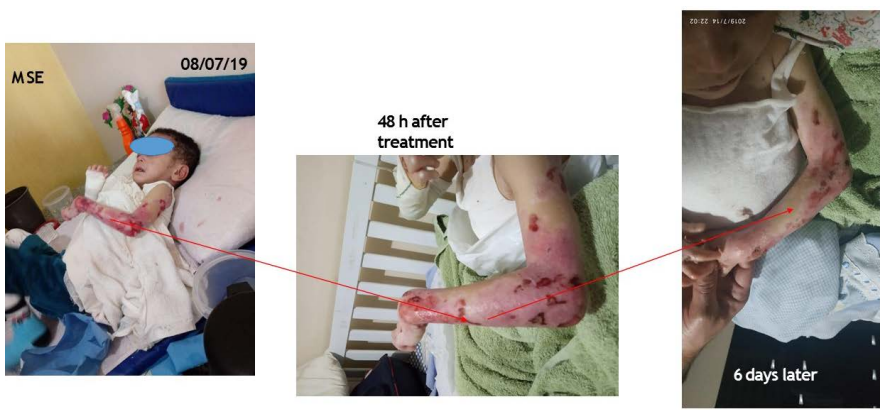

14/07/19

(b)

Figure 3. (a) Applying Nanoskin ACT, Nanoskin ACT soft for Eb treatment; (b) The evolution of Eb treatment by Nanoskin ACT, Nanoskin ACT soft.

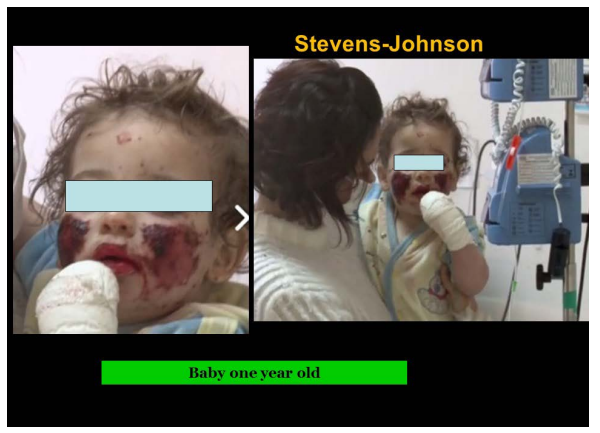

(a)

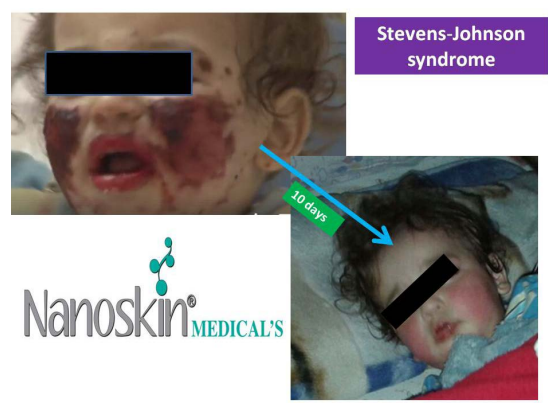

(b)

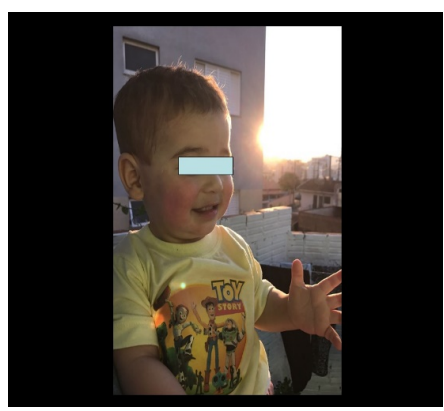

(c)

Figure 4. The evolution of Stevens-Johnson syndrome treatment by Nanoskin ACT, and Nanoskin ACT SOFT. 


\section{Conclusions}

NANOSKIN advanced cell therapy (ACT) and Nanoskin ACT soft perform the tasks necessary for tissue formation, maintenance, regulation and function, providing a powerful means of controlling the biological performance of regenerative materials.

The Nanoskin ACT and nanoskin ACT Soft wound dressing performed significantly better than the classical wound dressing on all parameters. Our results demonstrated that the Nanoskin ACT and Nanoskin ACT Soft wound dressing significantly reduced percentage wound area and the average time for complete wound closure compared with the classical wound dressing.

\section{Acknowledgements}

The author would like to thank to the Multipurpose Gamma Irradiation Facility-CETER/IPEN.

\section{Conflicts of Interest}

The authors declare no conflicts of interest regarding the publication of this paper.

\section{References}

[1] Fine, J.D. (2010) Inherited Epidermolysis Bullosa: Past, Present, and Future. Annals of the New York Academy of Sciences, 1194, 213-222.

https://doi.org/10.1111/j.1749-6632.2010.05463.x

[2] Pai, S. and Marinkovich, M.P. (2002) Epidermolysis Bullosa: New and Emerging Trends. American Journal of Clinical Dermatology, 3, 371-380. https://doi.org/10.2165/00128071-200203060-00001

[3] Pope, E., Lara-Corrales, I., Mellerio, J., et al. (2012). A Consensus Approach to Wound Care in Epidermolysis Bullosa. Joint American Academy of Dermatology, 67, 904-917. https://doi.org/10.1016/j.jaad.2012.01.016

[4] Denyer, J. and Pillay, E. (2012) Best Practice Guidelines for Skin and Wound Care in Epidermolysis Bullosa. International Consensus. DEBRA. https://www.woundsinternational.com/download/resource/5978

[5] Dhivya, S., Padma, V.V. and Santhini, E. (2015) Wound Dressings-A Review. Biomedicine ( Taipei), 5, 22. https://doi.org/10.7603/s40681-015-0022-9

[6] Cowan, L.J. and Stechmiller, J. (2009) Prevalence of Wet-to-Dry Dressings in Wound Care. Advances in Skin \& Wound Care, 22, 567-573. https://doi.org/10.1097/01.ASW.0000363469.25740.74

[7] Ellender, R.P., Peters, C.W., Albritton, H.L., Garcia, A.J. and Kaye, A.D. (2014) Clinical Considerations for Epidermal Necrolysis. Ochsner Journal, 14, 413-417. https://www.ncbi.nlm.nih.gov/pubmed/25249808

[8] Mockenhaupt, M. (2014) Stevens-Johnson Syndrome and Toxic Epidermal Necrolysis: Clinical Patterns, Diagnostic Considerations, Etiology, and Therapeutic Management. Seminars in Cutaneous Medicine and Surgery, 33, 10-16. https://doi.org/10.12788/j.sder.0058

[9] Schwartz, R.A., McDonough, P.H. and Lee, B.W. (2013) Toxic Epidermal Necroly- 
sis: Part I. Introduction, History, Classification, Clinical Features, Systemic Manifestations, Etiology, and Immunopathogenesis. Joint American Academy of Dermatology, 69, 173.e1-13. https://doi.org/10.1016/j.jaad.2013.05.003

[10] Lee, H.Y. and Chung, W.H. (2013) Toxic Epidermal Necrolysis the Year in Review. Current Opinion in Allergy and Clinical Immunology, 13, 330-336. https://doi.org/10.1097/ACI.0b013e3283630cc2

[11] Al Mualla, S., Farahat, R., Basmaji, P., de Olyveira, G.M., Costa, L.M.M., da Costa Oliveira, J.D. and Francozo, G.B. (2018) Special Nanoskin-ACT-Biological Membranes from Deep Wounds. Journal of Biomaterials and Nanobiotechnology, 9 , 79-88. 